\title{
ESTIMASI VALUE AT RISK MENGGUNAKAN VOLATILITAS DISPLACED DIFFUSION
}

\author{
Miranda Novi Mara Dewi ${ }^{1 \S}$, Komang Dharmawan ${ }^{2}$, Kartika Sari $^{3}$ \\ ${ }^{1}$ Program Studi Matematika, Fakultas MIPA - Universitas Udayana [Email: miranda.novi@yahoo.com] \\ ${ }^{2}$ Program Studi Matematika, Fakultas MIPA - Universitas Udayana [Email: k.dharmawan@unud.ac.id] \\ ${ }^{3}$ Program Studi Matematika, Fakultas MIPA - Universitas Udayana [Email: sarikaartika@unud.ac.id] \\ ${ }^{\S}$ Corresponding Author
}

\begin{abstract}
Value at Risk (VaR) is a measure of risk that is able to calculate the worst possible loss that can occurs to stock prices with a certain level of confidence and within a certain period of time. The purpose of this study was to determine the VaR estimate from PT. Indonesian Telecommunications by using Displaced Diffusion volatility. The Displaced Diffusion Model is a stochastic volatility model that describes changes in a financial asset assuming volatility is not constant, but follows a stochastic process. Displaced Diffusion model are capable of modelling skewed implied volatility structures and frequently applied by interest rate quants. Based on the estimation of Displaced Diffusion volatility, it is found that volatility for PT. Indonesian Telecommunications is 0.010168 and VaR estimation using Displaced Diffusion volatility with a confidence level of 95 percent of $1.63 \%$.
\end{abstract}

Keywords: Displaced Diffusion, Risk, Stochastic, Value at Risk, Volatility

\section{PENDAHULUAN}

Beberapa tahun belakangan ini investasi mulai menjadi tren yang sering dibicarakan oleh masyarakat. Saat ini bukan hanya masyarakat yang sudah mapan dalam hal keuangan tetapi banyak kalangan muda sudah mulai mencoba untuk berinvetasi. Namun dalam investasi tidak terlepas dari risiko. Risiko tidak dapat dihindari namun dapat diminimalisasi. Risiko merupakan penyimpangan keuntungan yang sesungguhnya (actual return) dari tingkat keuntungan yang diharapkan (expected return). Risiko dapat berupa peningkatan suku bunga, penurunan harga saham, inflasi dan sebagainya. Banyak hal yang menyebabkan terjadinya risiko sehingga diperlukan alat ukur yang dapat digunakan untuk mengukur dan mengelola suatu risiko. Metode yang berkembang pesat dan sangat populer digunakan untuk mengukur risiko adalah Value at Risk (VaR) yang dipopulerkan oleh J.P. Morgan dan dianggap sebagai metode standar dalam mengukur risiko (Pratiwi, 2014).

Value at Risk (VaR) merupakan suatu ukuran risiko yang dapat menghitung besarnya kerugian terburuk yang terjadi pada harga saham dengan tingkat kepercayaan tertentu dan dalam interval waktu tertentu. VaR telah banyak diaplikasikan untuk manajemen risiko finansial karena konsepnya sederhana, mudah dalam perhitungan, dan dapat diterapkan secara langsung (Yamai \& Yoshiba, 2005). Terdapat beberapa metode untuk menghitung VaR yaitu metode parametrik (disebut juga metode varians kovarians), metode simulasi Monte Carlo dan simulasi historis.

Selain metode, yang perlu diperhatikan dalam menghitung $\mathrm{VaR}$ adalah volatilitas. Volatilitas adalah suatu ketidakpastian dari deret waktu keuangan atau risiko yang mungkin dihadapi investor dalam perdagangan saham (Hartono, 2003). Mengestimasi volatilitas yang tepat dan sesuai keadaan pasar sangatlah penting bagi investor dan pelaku ekonomi, karena menjadi alat ukur risiko dalam investasi (Poon \& Granger, 2003). Jika salah mengestimasi volatilitas, maka akan salah dalam menentukan harga saham. Para investor dapat mengontrol dan mengurangi risiko dengan cara mengestimasi volatilitas melalui proses pemodelan

Model yang digunakan untuk mengesti-masi volatilitas antara lain adalah ARCH, GARCH, ARMA, Stochastic Volatility (Hwang \& Satchell, 2000). Dari beberapa model yang 
disebutkan, model Stochastic Volatility lebih unggul dibandingkan dengan model GARCH, karena mengasumsikan volatilitas suatu aset mengikuti proses stokastik dan bukan konstan (Kim et al, 1998).

Terdapat berbagai model dalam mengukur Stochastic Volatility salah satunya adalah model Displaced Diffusion (DD). Model Displaced Diffusion merupakan model untuk mengestimasi volatilitas yang bersifat stokastik. Model ini berbeda dengan model Black Scholes yang mengasumsikan volatilitas bersifat konstan. Model Black-Scholes, yaitu model yang mengasumsikan bahwa volatilitas yang mendasarinya konstan sepanjang umur aset dan tidak terpengaruh terhadap perubahan tingkat harga saham. Selain itu, pergerakan harga saham sulit untuk diprediksi karena umumnya fluktuasi harga saham bergerak secara random. Perhitungan menggunakan model Displaced Diffusion dapat menghasilkan perhitungan yang lebih akurat karena mempertimbangkan volatilitas yang berubah-ubah sesuai kondisi nyata di pasar.

Model Displaced Diffusion pertama kali dikembangkan oleh Rubinstein (1983). Model Displaced Diffusion merupakan model Stochastic Volatility yang menggambarkan perubahan suatu aset finansial dengan mengasumsikan volatilitas tidak konstan, namun mengikuti proses stokastik. Model ini mampu memodelkan struktur kemiringan dari implied volatility dan sering digunakan untuk mengetahui tingkat suku bunga.

\section{Return}

Return saham merupakan salah satu faktor yang mendorong para investor berinvestasi dan merupakan tingkat pengembalian yang dapat memperlihatkan keuntungan maupun kerugian. Perhitungan tingkat pengembalian (return) dirumuskan sebagai (Danielsson, 2011).

$$
R_{t}=\ln \frac{S_{t}}{S_{t-1}}
$$

dengan $R_{t}$ merupakan return saham pada periode ke- $t$ dan $S_{t}$ merupakan harga saham pada periode waktu ke-t. Apabila $\bar{R}$ menotasikan rata-rata return saham, maka

$$
\bar{R}=\frac{1}{n} \sum_{t=1}^{n} R_{t} .
$$

Model Black-Scholes

Model Black-Scholes dikembangkan oleh Fischer Black dan Myron Scholes, persamaan Black-Scholes dirumuskan sebagai (Black dan
Scholes, 1973)

$$
C_{B S}=S_{t} N\left(d_{1}\right)-K e^{-r(T)} N\left(d_{2}\right) .
$$

\section{Implied Volatility}

Implied volatility adalah penaksiran volatilitas yang dalam penentuannya mengasumsikan bahwa harga opsi di pasar modal sama dengan harga teoritis yang dihitung menggunakan model Black-Scholes, atau dapat ditulis sebagai (Dharmawan \& Widana, 2011).

$$
C_{o b s}(\sigma)=C_{B S}
$$

\section{Model Displaced Diffusion}

Model Displaced Diffusion standar (Kienitz and Wetterau, 2012) didefinisikan dalam persamaan diferensial stokastik sebagai berikut:

$$
d S_{t}=\mu\left(S_{t}+a\right) d t+\sigma_{D D}\left(S_{t}+a\right) d W t .
$$

Dengan menggunakan pricing formula Rebonato memperlihatkan harga beli dapat diubah dengan taraf ketetapannya yang layak. Mulai dengan menggunakan Black-scholes standar dengan $K=S_{0}$ dapat ditulis sebagai (Rebonato, 2004).

$$
C\left(\sigma_{B S}\right)=S_{0}\left[N\left(d_{1}\right)-N\left(d_{2}\right)\right]
$$

Dari persamaan Black-scholes standar pada persamaan (3) diperoleh nilai volatilitas displaced diffusion

$$
\sigma_{D D} \simeq \frac{\frac{s_{0}}{S_{0}+a} \sigma_{B S}\left(1-\frac{1}{24} \sigma_{B S}^{2} T\right)}{1-\frac{1}{24}\left(\frac{S_{0}}{S_{0}+a} \sigma_{B S}\right)^{2} T} .
$$

Selanjutnya akan dihitung nilai $\mathrm{VaR}$ dengan menggunakan persamaan

$$
\operatorname{VaR}_{\alpha}=\mu+\phi^{-1}(\alpha) \sigma_{D D}
$$

\section{METODE PENELITIAN}

Data yang digunakan dalam penelitian ini adalah data kuantitatif. Dalam penelitian ini data kuantitatif yang digunakan berupa data harian harga penutupan (close price) saham yang diperoleh dari PT. Telekomunikasi Indonesia selama satu tahun, dimulai dari 9 Juli 2018 sampai dengan dari 9 Juli 2019 yang diakses melalui http://finance.yahoo.com/. Langkahlangkah dalam mengestimasi nilai Value at Risk menggunakan volatilitas Displaced Diffusion:

1. Mengumpulkan data harga saham harian selama periode waktu 9 Juli 2018 sampai dengan dari 9 Juli 2019.

2. Menentukan nilai return dari data saham yang digunakan menggunakan persamaan (1)

3. Menghitung nilai rata-rata return saham menggunakan persamaan (2) 
4. Menetapkan nilai harga saham awal $\left(S_{0}\right)$, waktu jatuh tempo (T), parameter displacement parameter $(a)$, dan mengestimasi volatilitas Black-Scholes $\left(\sigma_{B S}\right)$.

5. Mengestimasi Implied Volatility menggunakan persamaan Black-Scholes dengan cara berikut;

a. Menentukan dan mencari turunan pertama fungsi volatilitas menggunakan persamaan (3).

b. Menyelesaikan persamaan dari turunan pertama fungsi volatilitas menggunakan metode numerik, yakni metode NewtonRaphson.

6. Mengestimasi volatilitas Displaced Diffusion PT. Telekomunikasi Indonesia menggunakan persamaan (5).

7. Mengestimasi Value at Risk saham dengan volatilitas Displaced Diffusion menggunakan persamaan (6).

8. Interpretasi hasil.

\section{HASIL DAN PEMBAHASAN}

Data yang digunakan dalam penelitian ini berupa data harian harga penutupan (close price) saham yang diperoleh dari PT. Telekomunikasi Indonesia selama satu tahun periode waktu 9 Juli 2018 sampai dengan dari 9 Juli 2019 sebanyak 252 keluaran saham. Data tersebut digunakan untuk menentukan return saham PT. Telekomunikasi Indonesia. Langkah-langkah dalam menentukan value at Risk menggunakan volatilitas Displaced Dffusion

1. Nilai return saham pada waktu $t$ dapat dihitung menggunakan data saham PT. Telekomunikasi Indonesia dengan menggunakan persamaan (1). Diperoleh return saham pada saat $t=1$ yaitu 0,011594 . Selanjutnya perhitungan return $t=2,3, \ldots, 251$ dapat dihitung dengan cara dengan yang sama.

2. Nilai rata-rata return saham PT. Telekomunikasi Indonesia diperoleh sebesar 0,000375

3. Parameter-Parameter yang Mempengaruhi Volatilitas Displaced Diffusion

a. Harga saham awal $\left(S_{0}\right)$

Karena harga saham yang digunakan adalah harga penutupan saham harian PT. Telekomunikasi dari 9 Juli 2018 sampai dengan 9 Juli 2019, maka harga saham awal yang digunakan adalah harga penutupan saham tanggal 9 Juli 2019, yaitu sebesar 30.15 b. Waktu jatuh tempo (T)

Waktu jatuh tempo ditetapkan selama satu tahun $(T=1)$.

c. Displacement parameter (a)

Nilai $a$ yang akan digunakan $a>0$

d. Nilai volatilitas Black-Scholes $\left(\sigma_{B S}\right)$ dapat diestimasi dengan implied volatility menggunakan persamaan sebagai:

$C_{o b s}-S_{t} N\left(d_{1}\right)+K e^{-r(T)} N\left(d_{2}\right)=0$

dengan memisalkan persamaan

$C_{o b s}-S_{t} N\left(d_{1}\right)+K e^{-r(T)} N\left(d_{2}\right)=f(\sigma)$

maka $f(\sigma)=0$ atau dapat ditulis sebagai:

$$
f(\sigma)=C_{o b s}-C_{B S}(\sigma)
$$

Untuk menentukan nilai $f(\sigma)$, bisa digunakan metode Newton-Rapshon dengan cara menentukan turunan pertama dari $f(\sigma)$ sebagai:

$$
\begin{aligned}
f^{\prime}(\sigma) & =-\left(\sqrt{T}\left(S_{t} \frac{1}{\sqrt{2 \pi}} e^{\frac{d_{1}{ }^{2}}{2}}\right)\right)+\frac{\partial_{d_{2}}}{\partial \sigma} \cdot 0 \\
& =-S_{t} \sqrt{T} \frac{1}{\sqrt{2 \pi}} e^{\frac{d_{1}{ }^{2}}{2}}
\end{aligned}
$$

Tabel 1. Iterasi volatilitas Black-Scholes menggunakan Newton-Raphson

\begin{tabular}{|c|c|c|c|}
\hline $\mathrm{i}$ & $x_{i}$ & $\sigma_{B S}$ & $\left|e_{r}\right|$ \\
\hline 1 & 0,06 & 0,018135 & 2,308 \\
\hline 2 & 0,018135 & 0,018142 & $4,06 \times 10^{-4}$ \\
\hline 3 & 0,018142 & 0,018142 & $4,39 \times 10^{-11}$ \\
\hline
\end{tabular}

Table 1, menunjukkan bahwa nilai volatilitas diperoleh pada iterasi ke-3 adalah $\sigma_{B S}=0,018142$ dengan error relative $4,39 \times 10^{-11}$

4. Estimasi volatilitas Black-Scholes dengan Metode Newton-Raphson yang diperoleh digunakan untuk menyelesaikan estimasi nilai volatilitas Displaced Diffusion. Adapun displacement parameter yang digunakan sebanyak 113 percobaan dengan rentang 0.5. Untuk menyelesaikan Estimasi volatilitas Displaced Diffusion menggunakan persamaan (5) dengan bantuan software MATLAB, diperoleh nilai estimasi volatilitas Displaced Diffusion berada pada rentang 0,0063126 sampai 0.017846 dan rata-rata sebesar 0,010168. Hasil estimasi yang disajikan dalam Tabel 2. merupakan sebagian hasil dari estimasi volatilitas Displaced Diffusion. 
Tabel 2. Volatilitas Displaced Diffusion

\begin{tabular}{|c|c|}
\hline$a$ & $\sigma_{D D}$ \\
\hline 0,5 & 0,017846 \\
\hline 1 & 0,01756 \\
\hline 1,5 & 0,017282 \\
\hline 2 & 0,017014 \\
\hline 2,5 & 0,016753 \\
\hline 3 & 0,0165 \\
\hline 3,5 & 0,016255 \\
\hline 4 & 0,016017 \\
\hline 4,5 & 0,015786 \\
\hline 5 & 0,015562 \\
\hline 5,5 & 0,015343 \\
\hline 6 & 0,015131 \\
\hline 6,5 & 0,014925 \\
\hline 7 & 0,014724 \\
\hline 7,5 & 0,014528 \\
\hline 8 & 0,014338 \\
\hline 8,5 & 0,014152 \\
\hline 9 & 0,013972 \\
\hline 9,5 & 0,013795 \\
\hline 10 & 0,013624 \\
\hline
\end{tabular}

Tabel 2, menunjukkan bahwa jika nilai displacement parameter yang digunakan semakin besar, nilai volatilitas Displaced Diffusion yang diperoleh semakin kecil dan ketika displacement parameter yang digunakan mendekati nol nilai volatilitas yang diperoleh tidak jauh berbeda dengan nilai volatilitas Black Scholes. Selain itu, apabila dilihat dari hasil perhitungan volatilitas Displaced Diffusion yang diperoleh nilai volatilitas selalu berubahubah bergantung pada nilai displacement parameter yang digunakan. Hal ini mengindikasikan bahwa volatilitas berubahubah sesuai kondisi nyata di pasar.

5. Mengestimasi Value at Risk dapat menggunakan persamaan (6) dibantu dengan software matlab. Hasil estimasi volatilitas Displaced Diffusion dan rata-rata return yang diperoleh sebelumnya akan digunakan untuk mengestimasi VaR. Dengan tingkat kepercayaan yang diguna-kan yaitu $95 \%$, dengan holding period 1 hari. Nilai Estimasi VaR menggunakan volatilitas Displaced Diffusion pada tingkat kepercayaan 95\% berada pada rentang 1,0008\% sampai dengan $2,8979 \%$ dengan rata-rata $1,63 \%$. Hal ini berarti apabila dimisalkan nilai investasi sebesar Rp1.000.000,00. maka besarnya nilai kerugian maksimum yang mungkin dialami satu hari ke depan pada tingkat kepercayaan 95\% yaitu sebesar
Rp289.790,00. sampai Rp100.080,00. dengan rata-rata akan mengalami kerugian maksimum sebesar Rp163.000,00.

\section{KESIMPULAN DAN SARAN}

\section{Kesimpulan}

Berdasarkan hasil dan pembahasan dapat disimpulkan bahwa nilai estimasi volatilitas Displaced Diffusion yang diperoleh selalu berubah-ubah bergantung pada nilai displacement parameter yang digunakan. Nilai estimasi volatilitas Displaced Diffusion berada pada rentang 0,017846 sampai dengan 0,0063126 dan rata-rata sebesar 0,010168. Dengan menggunakan nilai volatilitas tersebut, diperoleh nilai $\mathrm{VaR}$ pada tingkat kepercayaan 95\% berada pada rentang 2,8979\% sampai dengan $1,0008 \%$ dengan rata-rata $1,63 \%$.

\section{Saran}

Penulis menyadari bahwa estimasi Value at Risk menggunakan volatilitas Displaced Diffusion dalam tugas akhir ini masih memiliki banyak kekurangan. Adapun hal-hal yang disarankan untuk dijadikan pertimbangan dalam penelitian selanjutnya antara lain

1. Untuk pengembangan penelitian selanjutnya, diharapkan membanding-kan estimasi VaR menggunakan volatilitas Displaced Diffusion dengan volatilitas menggunakan model GARCH.

2. Penentuan harga kontrak opsi menggunakan volatilitas Displaced Diffusion.

\section{DAFTAR PUSTAKA}

Black, Fischer and Scholes, Myron. (1973). The Pricing of Options and Corporate Liabilities. The Journal of Political Economy, 81(3), 637-654

Danielsson, Jon. (2011). Financial Risk Forecasting. West Sussex England: John Wiley and Sons.

Dharmawan, K. dan Widana, I. N., (2011). Aplikasi Algoritma Biseksi dan NewtonRaphson dalam Menaksir Nilai Volatilitas Implied. Jurnal Matematika, 2(1), 1-5.

Hartono, Jogiyanto. (2003). Teori Portofollio dan Analisis Investasi, Edisi kelima. Yogyakarta: BPEE 
Kienitz and Wetterau, (2012). Financial Modelling: Theory, Implementation and Practice with MATLAB Source. England. John Wiley \& Sons.

Kim, S., Shephard, N., and Chip, S., (1998). Stochastic Volatility: Likelihood Inference and Comparison with ARCH Models. Economic Studies, 361-393.

Poon, Ser-Huang and Granger, C W. J., (2003). Forecasting Volatility in Financial Markets: A Review. Journal of Economic Literature, $41,478-539$.

Pratiwi, N., (2014). Estimasi Penyesuaian Likuiditas Terhadap Value at Risk Dengan Metode Varian Kovarian. Prosiding Seminar Nasional Aplikasi Sains \& Teknologi (SNAST), 10, 285-292.

Rebonato, R. (2004). Volatility and Correlation, 2nd edition. Chichester, New York: John Wiley \& Sons,

Rubinstein, M. (1983). Displaced Diffusion Option Pricing. Journal of Finance, 38(3), 213-217.

Yamai, Y. and Yoshiba, T., (2005). Value-atRisk Versus Expected Shortfall: A Practical Perspective. Jurnal of Banking \& Finance, 29, 997-1015. 